\title{
The home front: Internal organization of public affairs in Dutch subnational governments
}

\author{
Edward L. Figee | Jordy F. Gosselt | Paul C.J. Linders | Menno D.T. de Jong
}

Department of Communication Science, Faculty of Behavioural, Management and Social Sciences, University of Twente, Enschede, The Netherlands

\section{Correspondence}

Edward L. Figee, University of Twente, Department of Communication Science, Faculty of Behavioural, Management and Social Sciences, Enschede, The Netherlands. Email: e.l.figee@utwente.nl
Dutch subnational governments such as municipalities and provinces are increasingly compelled to express their interests in the national and European political arenas. Effectiveness in these arenas requires an optimal arrangement of Public Affairs (PA) activities in the subnational organization. Based on 41 in-depth interviews with prolific PA professionals and practitioners in the Netherlands, this article provides an overview of initiatives that subnational government organizations have to develop in their own organization after their "discovery" of how useful PA may be, but before the moment they enter the arenas. According to the participants, the creation of individual, collective, and regional commitment regarding PA is the first initiative. Subsequently, conditional and instrumental terms should be fulfilled, so that PA will be used as a tool to model PA messages. Concluding from the interviews, human aspects and internal cooperation determine the sensemaking of PA in a subnational organization, but a lack of arena knowledge frustrates this process.

\section{1 | INTRODUCTION}

In the US, Public Affairs (PA) has been well known for a long time, as processes of influence by interest groups (Dahl, 1956; Schattschneider, 1960; Truman, 1951; Xifra, 2015). In the Netherlands, PA entered the private sector around the 1960s and the public sector around the 1980s. As the public relations (PR) function turned out not to be sufficient for preventing and controlling conflicts with interest groups (Groenendijk, Hazekamp, \& Mastenbroek, 1997), more was needed to keep relations with interest groups going in case of disagreements. Public Affairs proved to be a helpful instrument and since then, next to the private sector, the public sector has also embraced PA (Groenendijk et al., 1997). However, PA has mostly been practiced by the central government (Van Schendelen, Bennis, \& Pauw, 1990), and hardly by subnational governments that are part of the larger system of government. In the Netherlands, subnational governments include municipalities (local government) and provinces (provincial government), with a constitutionally anchored autonomy, but with a financial connection to the central government. Together, these are defined as "decentralized unitary state". The mayor and the Commissioner of the King are appointed chairmen of the municipal council and the provincial council, respectively (Engels \& Fraanje, 2013). Although these subnational governments initially hardly embedded PA in their organizations, subnational authorities (including municipalities and provinces) saw themselves forced to think about the introduction of PA due to several governmental and societal changes. In this article, after addressing these influential changes, we focus on how subnational governments in the Netherlands organize themselves internally, in order to create external success in both the national and the European arena.

\section{1 | Governmental and societal changes leading to subnational PA}

The emergence of the European Union (EU) stimulated subnational PA, which was originally dedicated to steel and later on to agricultural interests (Pedler, 2005), and focused on rural regions. In 1986, the adoption of Single European Act, meant to create space for the internal market (including the regions), stimulated multilevel governance. Consequently, following the theory of multilevel governance, European integration has instigated "a policy creating process in which authority and policy-making influence are shared across multiple levels of government-subnational, national and supranational" (Mastenbroek, Zwaan, \& Liefferink, 2013; Van Hout, 2015). In this new reality, the influence on decision-making on the EU level is being shared between national government and subnational governments, and the subnational government would be able to influence the EU decision-making process independent from the national government (Van Hout, 2015). More specifically, when interests of the subnational actors and the government are different, it is crucial for subnational government to collect information about the background and intentions of European regulation (Mastenbroek et al., 2013). As a result of the growing EU 
and the emergence of subnational representations in the European arena, the public sector became more open to PA (Pedler, 2005). In the early years of the EU, lobbying had not particularly been considered a PA instrument yet, but it became a common activity in the European arena to raise European attention for (mostly agricultural) national and regional interests (Pedler, 2005). However, to Dutch subnational governmental administrations, PA is still relatively new (Van Schendelen, 2013).

Furthermore, the ongoing process of devolution (i.e., transmission of national tasks and powers from the national level towards subnational levels, intensified in the 1980s and since then permanently activated) was and is still influencing tasks and powers of subnational governments. More and more, the policy of the Dutch government is aimed at reducing national intervening while extending regional coordination (Mastenbroek et al., 2013). As a consequence, the responsibility for the execution of both European and national regulations becomes a matter of subnational authorities. For the time being, the apotheosis of this process is the 2015 devolution package deal in the government agreement Building Bridges (2012), which transfers the reduction of unemployment, care for the elderly, and youth care to the municipal level. This approach is characterized by the keyword "participation", introduced by the Dutch King in his first speech on September 17, 2013. In a parallel and comparative process, the Dutch provinces, in cooperation with municipal governments, have received more responsibilities throughout the years for social-economic and "green" development of regions, such as the execution of green European directives; rural and urban planning; and landscape and nature conservation. This long-term process of devolution is leading subnational authorities to more responsibility for the day-to-day running of society, with consequences for the internal municipal and provincial organization (Building Bridges, 2012).

Finally, since the 1970s, the confrontation with citizens has become more substantial (Van de Donk, 2014). Citizens' increasingly louder knock at the doors of national and subnational governments has become apparent. Citizen participation has become an almost magic word and a synonym for the creation of possibilities to reduce the distance to the subnational and national government under the well-known adage "think globally, act locally." In 1982, American politician Thomas Phillip O'Neill (1912-1994) said "All politics is local," giving vent to a general sense that subnational politics may be a determinant for civilian involvement in politics (Barber, 2013).

\section{2 | Subnational PA and the home front}

In this triangular wave of societal, governmental, and European changes, the subnational public sector has started to look for managerial instruments to get attention for its interests in national and European political arenas (Van Schendelen, 2013), knowing that PA activities such as lobbying create influence (Helland, 2008; McGrath, 2007; Vining, Shapiro, \& Borges, 2005). In general, a (financial) need and governmental attention to a particular problem at hand motivate subnational governments to decide to lobby (Loftis \& Kettler, 2015 Richter, Samphantharak, \& Timmons, 2009; Vining et al., 2005). Regarding the aspect of devolution, Van de Donk (2014) describes how subnational governments are arguing with the central government that is considered a centralistic-oriented power that remains the financial guard and holds financial reins. Subnational governments understand the power of the political environment in which they operate, externalize actions to influence that same environment, and tend to retain a lobbyist in an attempt to influence national and European policy (Loftis \& Kettler, 2015). Furthermore, the other subnational governments are increasingly becoming actors to pay attention to as well. As some regions are more successful in acquiring governmental attention and funding, cooperation at a subnational level is needed to neutralize this disparity (reference deleted for review purposes, 2016). However, this does not occur sufficiently, with the result that the national level does not believe that subnational cooperation can help solve problems, and that regions are not seen as "players": they are unknown.

Because of the many ongoing developments in the national and the European political arena, PA is permanently in development as well and therefore a subject of academic debate (Davidson, 2015; Derksen, 2015; McGrath, Moss, \& Harris, 2010; Van Schendelen, 2013). Toth (as cited in Botan \& Hazleton, 2006) describes how definitions of PA are pointing to "the building of relationships in the public policy arena" (p. 500), while referring to Grunig and Repper (1992), who stated that "Public Affairs applies to communication with government officials and other actors in the public policy arena" (p. 117-157). This demands internal managerial arrangements. Groenendijk et al. (1997) refer to the definitions of the PA manager, the Issue Management Specialist/ Director, the Government Relations Manager, and the Lobbyist, as formulated by the Public Relations Society of America in 1983 (Groenendijk et al., 1997). In general, PA is considered a managerial discipline meant to influence processes of decision-making in the public sector. As Linders and De Lange (2003) note: "PA is a strategic management discipline, directed to the political, administrative realm the organization is functioning in or will function in" (p. 17). For subnational governments, this means reconsidering their position regarding issues and themes they are or will possibly be involved in, and regarding relationships with public stakeholders, such as other subnational governments, private stakeholders, and the national and European arena. In this reconsideration, subnational governments have to think about possible organizational changes in order to arrange future PA operations; not by immediately embracing running issues and themes, but by primarily internalizing these issues and themes in processes of sensemaking in order to create support (Weick, 2009), and by considering how municipal of provincial influence may be effectuated in the national and European political arena (Van Schendelen, 2013). This may require civil servants and politicians who are willing to review their connections to the national and European arena, and their dayto-day work. It may even change the relationship of the home organization with private and (other) public stakeholders inside and outside the region, as well as the relationship with the national and European arena.

This is leading to the research question:

RQ: Regarding Public Affairs, what do Dutch subnational governments have to initially arrange internally, in order to create external success in the national and European arena later on? 


\section{2 | METHOD}

To find an answer to the research question, it is necessary to get insight in how municipalities and provinces prepare their organizations for the embedding of PA. To this end, qualitative interviews were held with actors who are involved in subnational decision- and policymaking and familiar with PA operations. We asked them to reflect on their experiences with PA in subnational circumstances.

\section{1 | Participants}

Forty-one participants were selected by snowball sampling, based on the extent to which their career is marked by political, administrative, and official functions in national and subnational government organizations, but always related to the interests of subnational government organizations. A distinction was made between PA practitioners and PA professionals. Public Affairs practitioners are persons practicing PA; not as a profession, but as a subnational official politician who is temporarily entrusted with PA activities. PA professionals are persons practicing PA as their profession; sometimes as a subnational civil servant, sometimes as a consultant. In other words, every PA professional is a PA practitioner, but not every PA practitioner is a PA professional. By means of snowball sampling, 41 respondents were recruited consisting of 24 full-time (public and private) Dutch subnational PA practitioners (mayors, aldermen, city clerks and civil servants connected with PA activities, Commissioners of the King (provinces), and Deputies (provinces) and 17 subnational PA professionals (municipal and provincial officials and consultants in the private sector, in The Hague and in Brussels, Members of Parliament, Members of the European Parliament (MEP)and (former) members of the central government who are familiar with subnational administrations). The interviews were not focused on comparing municipal and provincial PA practitioners (officials and politicians). After the 41 interviews, the data showed signs of saturation.

The participants were predominantly male (34 male; 7 female) and the average age of participants was approximately between 40 and 60 years. Throughout their career, the majority of participants had worked in (sometimes many) different administrative, governmental, and official functions related to subnational PA activities: 32 local, 26 provincial, 23 national, and 12 European functions; covering 93 functions in total. Some participants had started as a mayor in a municipality, sometimes became Commissioner of the King afterwards, or minister, or state secretary, or Member of Parliament/MEP, or vice versa. Others had also been a member of a local or regional ${ }^{1}$ and provincial council. Regarding the municipal level and the number of inhabitants, small municipalities were represented as well as big cities (ranging from less than 50.000 to more than 100.000 inhabitants). The provinces (or regions) that the participants represented were situated all over the country.

\footnotetext{
${ }^{1}$ In the Netherlands, cooperating municipalities and cooperating provinces are considered to be regional forms of subnational cooperation, sometimes with a regional council, which is however not constitutionally anchored and not democratically legitimated. Members of these (occasional) councils are also members of a municipal or provincial council, and thus democratically legitimated, but, as said, not in their regions.
}

Absolute anonymity was guaranteed because of the sensitivity of the topics in the interviews and the openness of the interviewees.

\section{2 | The interviews}

The main focus in the interviews covered four overall themes: (a) susceptibility of the national and European arena for subnational PA operations, (b) subnational government administrations' embedding of PA in their organizations before entering the arenas, (c) subnational government administrations' organization of PA operations when entering the arenas, and (d) competences of the subnational PA professional.

Most interviews lasted an hour and a half on average. Due to the promised secrecy, the participants talked uninhibitedly; not one question remained unanswered. The answers mostly covered more than the question was aimed at: Some interviews were no longer a "simple" Q\&A operation, but a narrative that related to separate items in the approach to be discussed. Probably due to the fact that almost all participants (had) occupied more than one governmental or administrative function at local, provincial (and regional), national, and/or European level, a broad spectrum of statements was created within the four themes.

The language in the interviews was Dutch. Due to planning and logistics, the interviews were held in municipal and provincial offices, at home, in Brussels, and in the International Press Centre of the House of Parliament in The Hague. The location was determined by wishes to speak in freedom and in secrecy, without any unrest or interference.

\section{3 | Analysis}

All interviews were transcribed verbatim. As a first step in the analysis, the first researcher captured the essence of every essential statement in a key phrase, no matter how extensive the statement was. This resulted in a total number of 1,003 key phrases.

As a second step, three independent coders checked all 1,003 key phrases by comparing these to the original interviews in order to assess their correctness and exhaustiveness. On average, $76 \%$ of the key phrases were confirmed without changes in this process. After discussing differences between the original key phrases and the interpretations of the independent coders, some of the key phrases were reformulated by changing a single word, some were reformulated by changing parts of the key phrase, and some new key phrases were added, which resulted in a total number of 1,050 key phrases.

The third step in the analysis involved the selection of key phrases that concerned the internal embedding of PA. Two independent coders divided all 1,050 key phrases in the four main categories covered by the interviews. The coders reached a Cohen's kappa of .72. Differences in their coding were discussed, after which consensus was reached about the best categorization. This procedure resulted in 173 key phrases that concerned the internal organization of PA, the focus of this article. ${ }^{2}$

\footnotetext{
${ }^{2}$ The other three topics in the interviews (i.e., arena susceptibility, external organizational aspects of subnational PA, and competences) are part of separate studies.
} 
The author and a coder were familiar with uncovering the issues as noted by the participants, and their analysis of the 173 key phrases was a process based on Grounded Theory (Corbin \& Strauss, 2008). Each key phrase was printed on a small piece of paper. Discussions started by repeatedly taking one printed key phrase from the pile of all 173 key phrases. When the discussions and debates indicated that key phrases were linked to a possible new aspect of the internal organization of PA, another pile was made. After several days of discussions and debates, the pile with 173 key phrases had been split up in five piles. Each pile illustrated an aspect of internal PA organization, namely: (a) the attitude of subnational politicians and civil servants towards PA; (b) PA "at home" (i.e., the way the subnational organization embeds PA in order to be able to create PA messages and to manage PA operations in the arenas later on); (c) the preparation of PA operations in order to gain a foothold in the arenas; (d) the creation of the PA message (i.e., giving content to the PA message by focusing, prioritizing, and fine-tuning); and (e) the professionals and practitioners in the subnational organization.

In a second round with a second coder who was also familiar with this subject, the separation between the five piles did not seem focused enough. After new debates, the five piles were integrated into three piles. The three final piles were translated into the following codes: (a) PA acceptance, which is the administrative and official acceptance of subnational PA in the organization and of the region as well, including the persons involved (politicians and officials) in order to be able to organize and manage PA operations in the national and European arena later on (28 key phrases); (b) PA embedding, which is preparing PA in the organization in order to enter the national and European arenas later on (116 key phrases); and (c) Message creation, which is the way the organization creates PA messages in order to prepare itself for the national and European arenas by using relevant knowledge, information, focusing, prioritizing, visioning, and finetuning (29 key phrases). The three codes were submitted to the regime of Cohen's kappa with .61 as result.

\section{3 | RESULTS}

Because of their broad spectrum of functions, the participants created a varied insight in how their organizations had to change and which steps they had to take to accept PA and to embrace PA as a new managerial discipline. In the interviews, the participants explained how PA was introduced in the organization, and described their experiences with PA acceptance, PA embedding, and message creation as antechambers to subnational PA. In our results, we present those utterances that illustrate the majority's opinions best or that provide more insight in the underlying process.

\section{1 | PA acceptance}

Individual and collective acceptance of PA determines the quality of subnational PA operations in the national and European arena. A municipal PA advisor in the European arena said that "local government officials should be enthusiastic [about PA]". Even in small, countryside municipalities, mostly (also) at a psychological distance from the
European arena, PA "can flourish when the official is enthusiastic about it". The official and the political management of a subnational government should "educate" relevant colleagues: "The town clerk and the mayor are the persons who have to advertise the necessity for an own PA policy in the municipal organization."

Municipal and provincial politicians prefer to be personally in charge of PA operations, besides the PA professional who is playing a supporting role and serving the political board. Politicians admit that they like to keep the reins, as a mayor and a city clerk said. "Municipal PA policy should be organized in such a way that no separate civil servant is needed and the local government politicians can do the PA work by themselves, thanks to the [well-coordinated] informational feeding from the subnational organization."

Individual acceptance creates collective acceptance, and collective acceptance creates commitment, professionals said. "European subnational PA policy can only function in the subnational organization if there is political and official commitment." But creating commitment is a long way to go, as a mayor explained, because "PA is not linked with the daily habitat of civil servants. . .the home organization should be willing to invest in PA [and] should accept and understand the importance of PA in the national and European arenas". This is influential in the case of subnational (i.e., regional) cooperation where PA is generally not a current theme, not even in a European context. Subnational cooperation occurs occasionally, based on the consideration that this creates a stronger position in the national and European arena.

"The national and European arenas are lacking in the regions," a municipal politician said. "The European arena is experienced in regions as far away and besides this [pointing at regional presence in Brussels], there is too little manpower," a regional official said. According to a Commissioner of the King, "for regions, the European arena is generally a menacing stranger who determines what will happen."

\section{2 | PA embedding}

To get PA embedded in the home organization, participants pointed at the selection of "the right persons" and at the necessity "to have a collective PA agenda with people who are able to carry out this agenda."

PA should be spread out in order to make PA-related arena information accessible for any other relevant colleague, including the management. "Administrative and official commitment in the subnational organization to European subnational PA demands the appointment of civil servants entrusted with 'European affairs' for judicial affairs, for European subsidy policy, and for financial, judicial, and policy effects of European policy in subnational interests."

Knowledge about political and administrative procedures, processes, habits, and traditions of the national and European arenas, knowledge about the ambitions of the subnational organization, and knowledge about the region create continuity in PA operations. The general message is: Knowledge must be there and if not, then knowledge should be "organized." An MEP suggested to intensify periodical meetings concentrated on arena knowledge, like some knowledge institutes are already doing, "to stimulate subnational PA in the national and European arena." A city clerk said: "Having outposts in 
the European arena is essential." But a G4 consultant ${ }^{3}$ said: "The subnational representatives in the European arena are understaffed."

"Pooling experienced, official capacity on call," "testing regional knowledge of persons with political ambitions," and "adding a national and a European paragraph in the administration of decision-making" were other suggestions for upgrading the knowledge level. Although plenty facilities are available for acquiring arena knowledge, the experience is that "it is hard for subnational politicians to get any idea about how to win in the European arena," according to a mayor. "Subnational governments are not aware of the threats and the chances as well, coming from Europe. ... Municipalities are lacking knowledge and consciousness about what 'Europe' can mean for them."

For provinces, the situation is hard as well. A subnational PA professional in Brussels referred to the interplay role that provinces could fulfill between the European arena and the national arena, concerning the process of devolution. But provinces are not succeeding: "Involvement, the ambition level, prioritizing, and expertise by experience determine whether provinces are able to deliver the right information to the European arena [but] the Dutch provinces have not developed intensively enough yet to be able to deliver information to the European arena that is needed in the home country to get decentralized national policy on the European agenda."

Subnational governments are involved in a growing number of policy issues, as a result of devolution, which requires permanent cooperation inside and outside the home organization. PA should be organized "collectively and well equipped," a mayor said. "If the subnational PA professional and the [local or regional] politician agree that a specific file should get more attention, this agreement should be brought to the relevant civil servant, [also] at the level of the daily, official shop floor.... The direct sharing of information in the subnational organization is essential for the organization of PA."

Cooperation between the PA professionals in the arena(s) and the municipal and provincial home organization in order to fine-tune PA messages and to avoid misunderstandings is essential, professionals said. "The PA professional in the national arena should get relevant signals from colleagues in the European arena in time... The subnational government should give its civil servants the time, and the management the opportunity to determine what files could be of any importance in the national arena and why."

The position of the PA professional in the subnational organization ("close to the administrative [governmental] Board" and "close to the top of the subnational organization") is a determining factor of the embedding process, because of information-sharing. The subnational PA professional is the one who is permanently "on the road" in the arenas, who is the physical label of the subnational organization, and who networks, collects information, and checks the extent of support. Participants described the position of the PA professional as vulnerable. The professional is the ("Ionesome") liaison officer, equipped and entrusted to deliver information, preferable in direct communication lines with the (top) management of the organization, which is decisive for the embedding process. The professional arranges this by himself

${ }^{3} \mathrm{G} 4$ means "the four big cities" (100.000+) in the Netherlands: Amsterdam, Utrecht, The Hague, and Rotterdam. In some files, they cooperate in the national and European arena. or with the help of the management, which requires well-organized internal support. "The lobby desk [as back office] of the province supports the lobbyist as a secretariat, supports the lobbyist in his issue management, entrusts PA to the lobbyist, and accepts that the lobbyist keeps in contact with the Board without any intervention. . . PA activities are not to be institutionalized too much, to avoid that 'a nation of [autonomous] islands' is growing [in the subnational organization]."

Participants said not to have a satisfying answer to the question to which extent the professional may be held accountable, due to sometimes uncertain (political) circumstances. Two private PA professionals said: "The subnational PA professional can be held accountable for the capability to create commitments and to develop support for files ...., but not for [possible] results of PA activities, because political circumstances can be very unpredictable."

A Commissioner of the King stated that the accountability of the PA professional should be in the hands of the politicians, because the professional has a foothold in political arenas, is connected with public interests, is permanently working in a political atmosphere, and must be able to negotiate when political situations suddenly change. "The subnational PA professional with an own network is a subnational diplomat; he is operating on behalf of a democratic government he has to be accountable to."

PA operations demand permanent coordination in the triangle of (a) the Board, (b) the PA professional in the arenas, and (c) private and (other) public stakeholders, in order to guard relationships and at the same time keep an eye on own interests, which is essential for embedding. Clear appointments about roles and functions are needed. A city clerk characterized the triangular coordination with the words: "The organization of [subnational] PA should not only be directed to 'get something' but also to 'bring something'. .. . [which means that] the local government determines the priorities, the official departments execute these priorities, and the PA professional goes to the arena with these priorities."

"Operations [in the arenas] without sufficient support [from the subnational organization and stakeholders] is an identification mark of Dutch PA. ... National and European PA does not stand a chance without support in the subnational organization", a mayor said. Subnational governments mix up lobby and PA, which causes confusion in the embedding process, which in turn causes confusion in the gaining of support. "Some provinces do not use the word 'PA' but the words 'lobby function' instead, [because] lobbying as a PA instrument can be specified, but PA as policy cannot."

Internal networking (as one of the main daily activities) of the PA professional with relevant subnational colleagues to involve them in PA operations contributes to embedding. "The subnational PA professional working for a [subnational] collective should invite the communication advisors of the collective partners to participate in his PA operations."

"Subnational governments sometimes fail in their PA, because they do not prepare their operations in the national arena well enough," a deputy experienced. PA operations should be sharply prepared ("at home"). The quality of these preparations contributes to embedding and to the quality of the message. "Regional members of Parliament are willing to push regional interests within their political 
parties in the House of Parliament when the region is able to substantiate its interests," a private regional PA practitioner said.

Regarding the European arena, the process of embedding is mainly driven by money, which might be the cause of rising competition between municipalities and provinces. "[Because of money-grubbing] subnational presence in the European arena is justified mostly by arguments of competition."

A Commissioner of the King who regularly visited the European arena said: "The European arena is a money machine for subnational governments. .. . Because the Dutch presence in the European arena is totally focused on funding and not on Europe, subnational cohesion is lacking. ... Subnational governments are not aware that they should place their projects in European perspective and in European contexts."

\section{3 | Message creation}

The better PA is embedded, the better the message can be created, and the more powerful the message, the higher the chance that the PA operation around this message will be successful, participants said. The PA message is the vehicle, which only thrives if PA is accepted and embedded, and furthermore, if the organization is prepared enough to keep this vehicle running. Participants mentioned dossier knowledge and focus as "engines" in this vehicle.

Dossier knowledge is required to compare the content of the current PA dossier with relevant arena information and with relevant persons in the arenas, in order to find out if sufficient support can be collected. Provincial and municipal participants referred to the necessity "to think pro-actively even during current PA operations." When political changes are coming up in the national arena, it must be possible to reorganize PA messages. Another possibility is to couple PA messages ("linking pins"), if those messages are "congruent enough," as a private manager of a subnational NGO said. "It would be good for the organization of subnational PA if lack of commitment can be banned by putting PA messages only in the hands of the fixed triangle: administrative expert, politician, and PA professional [and] if PA professionals of the same subnational organization [cooperate and] fine-tune their activities in the national and European arena with each other by exchanging information."

An essential element in the fine-tuning of PA messages is keeping an eye on what the subnational organization has in mind in the long run. "Without vision and without an agenda linked with that vision, it is impossible to develop subnational PA policy," a deputy said, who was supported by a municipal PA professional: "The success of subnational PA is dependent on vision about the future."

Having more than one issue makes the messenger fade away and "waters" the messages, as some mayors and provincial and municipal PA professionals said. "By continually focusing on one interest, subnational interests can 'touch' the national and European arena. . . . Regions are stuck in disagreement when they do not choose one collective theme and do not make use of their potential and power. . . In subnational PA, the focus should be directed to functional accounts more than to administrative and political accounts."

But the needed "clear goal" is predominantly where and how to find funding for projects. And although some provincial and municipal political participants are warning about the effects of this dominant monomania, the show must go on. "In the realization of subnational projects, money is more dominating than vision." ... "Regional PA in the national and European arena is focusing most of its time to the question which region is finding the best finance method with the best arguments." According to a regional managerial official, regions have to fight for their position, because regional financial interests have to weigh up against the (financial) position of the Netherlands as an EU member state; regional funding may become a consolation prize. The reason that subnational PA has become a fight for money is, according to a provincial PA professional, "quite simple: The fragmentation in the execution of subnational by the 'stress of too many choices to make."

\section{4 | DISCUSSION}

The main findings of this study can be summarized in the following observations.

Starting a process of embedding does not stand a chance without individual, collective, and regional acceptance of PA: Individual acknowledgement of the merits of PA may educate (relevant, regional) others to come to individual PA acceptance as well. This creates collective acceptance, also within regional cooperation. Acceptance creates embedding, and embedding creates support for substantial PA messages. The PA professional is the permanent "linking information pin" between the arenas and the (top of the) home organization. But politicians prefer to keep the reins in PA operations, because at the end of the day, the politician is the one who has to account for successes or failures in PA operations to the municipal or provincial council. Acceptance also means absorbing changes "from abroad," leaving old approaches, or at least reconsidering them (Weick, 2001).

Via acceptance and embedding, PA messages become substantial, in (political) weight as well as in (regional) support in order to keep in touch with the arenas. This means creation of continuity. Participants mention the availability of meeting points in the region and in the arenas. "A vision of the future," mentioned as an "engine" to keep PA messages going, remains meaningless when it is not connected to issues in the national and European arena. Also, Evers and Tennekes (2016) illustrate the importance of continuity in their research on Europeanization in spatial planning by directing to the mix of national and European legislation and local traditions, and the necessity to connect European, national, and local (regional) interests.

Dossier and arena knowledge play the ultimate role in acceptance and embedding, in order to involve private and (other) public stakeholders in the region and to involve the home organization itself. Involved stakeholders, officials, and politicians may propagate current PA messages as well. Periodical pooling and the creation of expert pools ("on demand") improve dossier and arena knowledge in the subnational organization. When those "poolers" know about PA, they are more capable of organizing effective "broadcasting" of relevant PA messages.

A leading component in the internal organization of subnational PA is developing "substantial" PA messages as an outcome of acceptance and embedding demands cooperation. Although this article mainly focuses on the internal organization of PA, cooperation with 
both private and public regional partners is important as well. ${ }^{4}$ Cooperation is the binding agent both inside the municipal and provincial home organization and outside in contacts with private and (other) public stakeholders, to connect them with PA messages and to bind common interests before entering the arenas, in order to come to "substantial" PA messages.

\section{1 | Final conclusion}

Returning to the research question (Regarding Public Affairs, what do Dutch subnational governments have to initially arrange internally, in order to create external success in the national and European arena later on?) and reflecting on the answers of participants, moments of sensemaking are visible. Weick (2001) described this as follows: ". . . people adapt to the life of continuous learning that they implanted in the first place to cope with the loss of boundaries" (p. 221). Weick labeled this as "moments of commitment" (p. 27). He compared the process of sensemaking to improvisational jazz, including failures as a result of improvisations; "only the echo of the composer's soul remains" (pp. 301-302). He referred to Nonaka and Takeuchi (1995), who said that "a one percent success rate is supported by mistakes made 99 percent of the time" (p. 232), and to Gioia (1988), who described "moments of rare beauty intermixed with technical mistakes and aimless passages" (p. 66).

This is what the results show as well: Subnational governmental organizations, talking about "fighting" to draw attention to their interests, apply PA to find out by trial and error what the most appropriate approaches are, in order to enter the national and European arena later on. Paraphrasing Weick's words (Weick, 2009): An organizational process of sensemaking creates familiarity with PA (at relevant levels in the organization), with which societal (i.e., citizens') interests could be connected to subnational governmental interests:

"Sense-making rather than decision-making may be the more central organizational issue" (p. 4). Sense-making creates new commitment: "What we need to understand are those events that give direction and meaning to the stream of organizational moments" (Weick, 2009, p. 27-28).

\subsection{Limitations and suggestions for future research}

In this study, the focus was on the embedding of PA in a general sense. Other aspects were banned out as much as possible, and only accepted when the connection to the internal process of embedding was pointed out by participants as inseparable. However, the diversity in the aspects that participants brought in points out that the internal process of organization of PA (i.e., the process in the subnational organization and in the region) is hard to separate from influences coming from the arenas ("outside"). For example, although the interviewees did not focus on the effects of processes of devolution on the embedding of PA, decentralization might affect how PA is arranged in the organization, because devolution is seen by the national government

${ }^{4}$ Cooperation with partners outside the region, for example, with neighboring subnational governments at the other side of the national border (Euregional cooperation) and also elsewhere in the EU (transregional cooperation), is subject of a separate study, as explained in Footnote 3. as an instrument to come "closer" to the citizen via subnational governments (Building Bridges, 2012). In future research, it is recommendable to find out what role the process of devolution plays in the preparation of PA policy at the subnational level to enter the national arena.

Second, because our sample of respondents consisted of both PA practitioners and PA professionals, it is suggested for further research to study whether differences exist in the way that subnational PA practitioners (i.e., nonprofessionals) who are temporary entrusted with PA accounts and PA professionals process PA messages. Also, in our study, PA operations and issues have not been linked to illustrate to which extent subnational governments are successful in their PA. This article only focused on the process of embedding PA at the subnational level, without issue casuistry. Future studies could try to connect the embedding of PA with actual organizational outcomes.

\section{REFERENCES}

Barber, B. R. (2013). If mayors ruled the world - Dysfunctional nations, rising cities. New Haven, CT: Yale University Press.

Botan, C., \& Hazleton, V. (2006). Public relations theory II. London, England: Lawrence Erlbaum.

Building Bridges. (2012). Government Agreement Rutte II administration, 29th of October 2012, chapters VII: 18-25; X:32; X11:40.

Corbin, J., \& Strauss, A. (2008). Basics of qualitative research. Los Angeles, CA: Sage.

Dahl, R. A. (1956). A preface to democratic theory. Chicago, IL: University of Chicago Press.

Davidson, S. (2015). Everywhere and nowhere: Theorising and researching public affairs and lobbying within public relations scholarship. Public Relations Review, 41(5), 615-627.

Derksen, J. W. (2015). Haagse oersoep - over de overheid en hoe het beter kan [The 'old mix' of department organizations - about the central administration and how to improve]. Den Haag, the Netherlands: Boom Bestuurskunde.

Engels, J. W. M., \& Fraanje, M. J. (2013). De bestuurlijke organisatie van Nederland - historie, grondslagen, werking en debat [The governmental organization of the Netherlands - history, constitution, processes and debate]. Deventer, the Netherlands: Wolters Kluwer.

Evers, D., \& Tennekes, J. (2016). Europe exposed: Mapping the impacts of EU policies on spatial planning in the Netherlands. European Planning Studies, 24(10), 1747-1765. doi:10.1080/09654313.2016.1183593

Gioia, T. (1988). The imperfect art. Oxford, England: Oxford University Press.

Groenendijk, J., Hazekamp, G., \& Mastenbroek, J. (1997). Public Relations Beleid, organisatie en uitvoering [Public relations - Policy, organization and execution]. Alphen aan den Rijn, the Netherlands: Samsom.

Grunig, J., \& Repper, F. (1992). Strategic management, publics and issues Excellence in public relations and communication management. Hillsdale, NJ: Lawrence Erlbaum Associates.

Helland, L. (2008). Lobbying with conflicting interests: Norwegian localcentral relations. European Journal of Political Research, 47(2), 184-205.

Linders, P. C. J., \& De Lange, R. (2003). Public Affairs \& Werkelijkheidsconstructie [Public Affairs \& Constructions of Reality]. Enschede, the Netherlands: University of Twente.

Loftis, M. W., \& Kettler, J. J. (2015). Lobbying from inside the system: Why local governments pay for representation in the U.S. Congress. Political Research Quarterly, 68(1), 193-206. doi:10.1177/10659/29/4563764

Mastenbroek, E., Zwaan, P., \& Liefferink, D. (2013). Provinciaal positiespel in Brussel en Den Haag - een onderzoek naar de positie van provincies in Europese besluitvorming [Provinces' play for a position in Brussels and The Hague - research on the position of provinces in European processes of decision-making]. Nijmegen, the Netherlands: Radboud University, Institute for Management Research. 
McGrath, C. (2007). Framing lobbying messages: Defining and communicating political issues persuasively. Journal of Public Affairs, 7(3), 269-280.

McGrath, C., Moss, D., \& Harris, P. (2010). The evolving discipline of PA. Journal of Public Affairs, 10(4), 335-352. doi:10.1002/pa.369

Nonaka, I., \& Takeuchi, H. (1995). The knowledge-creating company: how Japanese companies create the dynamics of innovation. Oxford, England: Oxford University Press.

Pedler, R. (2005). The history and development of public affairs in the European Union and the United Kingdom. In P. Harris, \& C. S. Fleisher (Eds.), The handbook of public affairs. (pp. 50-55). London: SAGE. 10.4135/ 9781848608108.n3

Richter, B. K., Samphantharak, K., \& Timmons, J. F. (2009). Lobbying and taxes. American Journal of Political Science, 53(4), 893-909.

Schattschneider, E. E. (1960). The semisovereign people. New York, NY: Holt, Rinehart and Winter.

Truman, D. B. (1951). The government process. New York, NY: Knopf.

Van de Donk, W.B.H.J. (2014). De centralisatie in openbaar besturen over dunne denkramen, pertinente pragmatiek en ambivalente ambities, $11^{\mathrm{e}}$ ROB lezing 2014, 12 november 2014 [The centralization in government - about weak frameworks, firm pragmatism and ambivalent ambitions, $11^{\text {th }}$ lecture Council for Public Management 2014, 12 November 2014].

Van Hout, M. (2015). The European Lobby of the Regions: Analyzing the impact of the EU lobbying behaviour of the Dutch provinces on the gatekeeping powers of the central government (Unpublished doctoral thesis). Leiden University, Leiden, the Netherlands.

Van Schendelen, M. P. C. M. (2013). The art of lobbying the EU - More Machiavelli in Brussels. Amsterdam, the Netherlands: University Press.

Van Schendelen, M. P. C. M., Bennis, W. J., \& Pauw, B. M. J. (Eds) (1990). Lobbyen, hoe werkt 't? [Lobbying, how does it work?]. Den Haag, the Netherlands: SDU.

Vining, A. R., Shapiro, D. M., \& Borges, B. (2005). Building the firm's political (lobbying) strategy. Journal of Public Affairs, 5(2), 150-175.

Weick, K. E. (2001). Making sense of the organization. Malden, MA: Blackwell Publishing Ltd.

Weick, K. E. (2009). Making sense of the organization, volume II - The impermanent organization. Chichester, England: John Wiley \& Sons Ltd.

Edward Figee started his working life in the 1970s as a parliamentary journalist for regional printed media and ended his career in 2011 as regional and local public affairs professional in the Dutch House of Parliament. During his professional life, he was involved in processes decentral governments developed to gain access to the national and European political arenas.
These processes are the main topic of his research as a $\mathrm{PhD}$ candidate at the University of Twente (The Netherlands).

Jordy Gosselt is an assistant professor of Communication Science at the University of Twente (The Netherlands). The central topic of his research concerns public relations and technology. Based on validated conceptual frameworks in the fields of information systems and communication, including the notion of technology affordances, public relations, and public affairs, he focuses on how organizations may benefit from media relations and public affairs activities in order to enhance their corporate communications with external stakeholders.

Paul Linders worked in various management positions at internationally operating enterprises (AkzoNobel and Sara Lee) and was a senior consultant at an international consultancy group for public affairs and communication. In the 1990s, he was the owner and managing director of two successful agencies for marketing, communication, and fundraising. Since 2000, he has been active in higher education at the University of Applied Sciences Utrecht and the University of Twente. In 2016, he was appointed as professor of Governance and Sustainability at the Technological University of the Americas.

Menno de Jong is a full professor of Communication Science at the University of Twente (The Netherlands). His research interests include the domains of organizational and technical communication. Among the research topics he addressed in recent research are public affairs, communication audits, corporate visual identity management, and corporate social responsibility. He was the editor of the Society of Technical Communication's flagship journal Technical Communication between 2009 and 2015.

How to cite this article: Figee EL, Gosselt JF, Linders PCJ, de Jong MDT. The home front: Internal organization of public affairs in Dutch subnational governments. J Public Affairs. 2017;17:e1641. https://doi.org/10.1002/pa.1641 